\title{
A review of the methodological features of systematic reviews in maternal medicine
}

\author{
Lumaan Sheikh$^{1}$, Shelley Johnston ${ }^{1}$, Shakila Thangaratinam*1,2, \\ Mark D Kilby ${ }^{1}$ and Khalid S Khan ${ }^{1}$
}

\begin{abstract}
Address: ${ }^{1}$ Academic Unit, Birmingham Women's Hospital, University of Birmingham, Birmingham B15 2 TG, UK and ${ }^{2}$ Clinical Lecturer in Obstetrics and Gynaecology and Clinical Epidemiology, Academic Unit, 3rd floor, Birmingham Women's Hospital, Birmingham B15 2TG, UK

Email: Lumaan Sheikh - lumaan.sheikh@aku.edu; Shelley Johnston - thomasina-tittlemouse@ hotmail.co.uk;

Shakila Thangaratinam* - s.thangaratinam@bham.ac.uk; Mark D Kilby - kilbymd@adf.bham.ac.uk; Khalid S Khan - k.s.khan@bham.ac.uk

* Corresponding author
\end{abstract}

Published: 24 May 2007

BMC Medicine 2007, 5:10 doi:10.1186/1741-70/5-5-10
Received: 7 August 2006

Accepted: 24 May 2007

This article is available from: http://www.biomedcentral.com/I74I-70I5/5/10

(C) 2007 Sheikh et al; licensee BioMed Central Ltd.

This is an Open Access article distributed under the terms of the Creative Commons Attribution License (http://creativecommons.org/licenses/by/2.0), which permits unrestricted use, distribution, and reproduction in any medium, provided the original work is properly cited.

\begin{abstract}
Background: In maternal medicine, research evidence is scattered making it difficult to access information for clinical decision making. Systematic reviews of good methodological quality are essential to provide valid inferences and to produce usable evidence summaries to guide management. This review assesses the methodological features of existing systematic reviews in maternal medicine, comparing Cochrane and non-Cochrane reviews in maternal medicine.
\end{abstract}

Methods: Medline, Embase, Database of Reviews of Effectiveness (DARE) and Cochrane Database of Systematic Reviews (CDSR) were searched for relevant reviews published between $200 \mathrm{I}$ and 2006. We selected those reviews in which a minimum of two databases were searched and the primary outcome was related to the maternal condition. The selected reviews were assessed for information on framing of question, literature search and methods of review.

Results: Out of 2846 citations, 68 reviews were selected. Among these, 39 (57\%) were Cochrane reviews. Most of the reviews $(50 / 68,74 \%)$ evaluated therapeutic interventions. Overall, 54/68 (79\%) addressed a focussed question. Although 64/68 (94\%) reviews had a detailed search description, only $17 / 68(25 \%)$ searched without language restriction. $32 / 68(47 \%)$ attempted to include unpublished data and I I/68 (16\%) assessed for the risk of missing studies quantitatively. The reviews had deficiencies in the assessment of validity of studies and exploration for heterogeneity. When compared to Cochrane reviews, other reviews were significantly inferior in specifying questions (OR 20.3, 95\% Cl I.I-38I.3, $\mathrm{p}=0.04$ ), framing focussed questions (OR 30.9, 95\% Cl 3.7256.2, $\mathrm{p}=0.00 \mathrm{I})$, use of unpublished data (OR 5.6, 95\% Cl I.9-16.4, $\mathrm{p}=0.002)$, assessment for heterogeneity $(\mathrm{OR} 38 . \mathrm{I}, 95 \% \mathrm{Cl} 2.1,688.2, \mathrm{p}=0.0 \mathrm{I})$ and use of meta-analyses (OR 3.7, 95\% Cl I.310.8, $\mathrm{p}=0.02$ ).

Conclusion: This study identifies areas which have a strong influence on maternal morbidity and mortality but lack good quality systematic reviews. Overall quality of the existing systematic reviews was variable. Cochrane reviews were of better quality as compared to other reviews. There is a need for good quality systematic reviews to inform practice in maternal medicine. 


\section{Background}

Maternal medicine has emerged as an increasingly important area for the obstetricians dealing with high risk pregnancies. It involves care of women with medical complications of pregnancy which may be specific to or predate the pregnancy [1]. Approximately half of complex pregnancies are related to an abnormal fetal or obstetric factor, whereas medical diseases constitute the remainder of this high risk obstetric population. Scientific developments in internal or general medicine have led to newer diagnostic and therapeutic strategies to manage medical diseases. The physiological changes during pregnancy can affect not only the clinical presentation of a medical problem but may give rise to difficulties in diagnosing and managing these problems. In order to provide the best possible quality of care to women with complicated pregnancies obstetricians dealing with the high risk obstetric cases should have evidence based knowledge on the diagnostic, therapeutic and prognostic aspects of maternal medicine.

Recently there has been a proliferation of systematic reviews as one of the key tools for evidence-based medicine [2]. As maternal medicine covers the issues related to pregnancy as well as general medicine, research evidence is scattered in the literature making it difficult to access information for clinical decision making. Systematic reviews provide a way forward as individual pieces of research can be collected within literature reviews and if appropriate subjected to meta-analysis [3]. Good methodological quality is essential for these reviews to have valid inferences and to produce usable evidence summaries to guide the obstetric management [4]. This study examines the methodological features of recently published systematic reviews in maternal medicine and specifically compares Cochrane to non-Cochrane reviews.

\section{Methods}

To determine the quality of current systematic reviews in maternal medicine, we developed a priori protocol based on recommended methods [2,5-7].

A computerised search of publicly available databases was conducted. Ovid Medline (1996 to date), Embase (1996 to date), Database of Reviews of Effectiveness and Cochrane Database of Systematic Reviews were searched for relevant reviews published between 2001 and 2006. Key word combinations like Pregnan\$, Matern\$, Gestation\$, Obstetric\$, Complication\$, Systematic review\$ and Meta analys $\$$ were used for the search strategy in addition to word variants, subject headings and free text. The \$ sign is a truncator used to capture any word that begin with the letters in front of the \$ sign in the search terms used. Additionally common and specific medical problems related to pregnancy were searched using key words describing names of the disease such as Pre eclampsia, Hypertension, Diabetes, Cholestasis, Anaemia, Thrombocytopaenia, Thrombophilia, and Thromboembolism. Hand search of reference lists was conducted of all relevant articles to identify any missing reviews. The searches were limited to reviews between 2001 and 2006 due to increasing developments in the field of maternal medicine in recent years. Inclusion criteria required a minimum of two publicly available databases searched for a medical condition specific to or predating pregnancy and maternal factor as the primary outcome. We searched without language restrictions. All the reviews with fetal or neonatal factor as the primary outcome were excluded.

Two reviewers independently extracted and assessed the data according to a checklist formulated as part of our protocol (Table 1). The methodological quality of each review was assessed by focussing on framing of the question, literature search and review methods scrutinising methods of literature search and data synthesis. The items assessed internal validity and explicitness of reporting, both of which are important issues in quality of reviews. Differences between reviewers were resolved by discussion. We computed rates of compliance with the items in our checklist and compared Cochrane and non-Cochrane reviews. Odds ratios and their 95\% confidence intervals were computed. All statistical analysis was performed using Stata 8.0 statistical package.

\section{Results}

The initial literature search resulted in 2864 citations. Of these 68 reviews [8-75] fulfilled the inclusion criteria and were selected for detailed study (Fig 1). A total of 39 (57\%) Cochrane reviews [8-46] and 29 (43\%) non Cochrane reviews [47-75] were included. Most of the reviews assessed therapeutic interventions (50/68, 74\%), and the rest were reviews on prognosis $(12 / 68,17 \%)$ and diagnosis $(6 / 68,9 \%)$. The range of clinical topics dealt with by the reviews is shown in Fig 2.

Overall quality of the existing systematic reviews was variable (Fig 3). Majority of the reviews (62/68, 91\%) specified the question and 54/68 (79\%) had a focussed question with clearly defined population and outcome measures. A large population of the reviews $(64 / 68,94 \%)$ had a detailed search description including databases searched and key words used. Almost half of the reviews $(32 / 68,47 \%)$ attempted to include unpublished data. However only $11 / 68(16 \%)$ assessed the risk of missing studies quantitatively and 17/68 (25\%) searched without language restriction. Almost all the reviews had good tabulation of results and characteristics of included studies (65/68, 96\%). 
Table I: Checklist used to assess the quality of systematic reviews included in the review.

\begin{tabular}{ll}
\hline Title & \\
Reference & \\
First Author & \\
Year of publication & \\
Journal & \\
Publication dates of literature included & \\
No. studies included in the review & \\
$\begin{array}{l}\text { No. of reviewers } \\
\text { Type of review }\end{array}$ & therapeutic/ \\
& prognostic/diagnostic \\
Framing of question: & \\
Question specified & yes/no \\
Question relevant & yes/no \\
Narrow focus of question & yes/no \\
Explicit testable hypothesis & yes/no \\
Literature search & \\
Adequate search description (incl. names of & yes/no \\
databases and search terms) & \\
Use of reference list & yes/no \\
Search without language restriction & yes/no \\
Assessment for risk of missing studies & yes/no \\
Inclusion of unpublished data & yes/no \\
Quality assessment of included studies: & \\
Potential sources of bias (ie. randomisation) & yes/no \\
Data collection (prospective/retrospective) & yes/no \\
Follow-up & yes/no \\
Blinding of assessors* & yes/no \\
Description of intervention* & yes/no \\
&
\end{tabular}

*applicable only to interventional reviews

The quality of Cochrane and non Cochrane reviews is given in Fig 3. Cochrane reviews [8-46] had specified the questions more often than non Cochrane reviews [4751,53-55,58-60,62-71,73-75] (OR 20.3, 95\% CI 1.1$381.3, \mathrm{p}=0.04$ ) and were also framed narrowly focussed questions specifying the population, interventions and comparisons, outcome of the study and the study design (OR 30.9, 95\% CI 3.7- 256.2, p = 0.001). Cochrane reviews attempted more often to include unpublished data in literature search (OR 5.6, 95\% CI 1.9-16.4, p = 0.002). Twelve out of 29 non-Cochrane reviews [48,50,53-55,64-66,68-71] performed a meta-analysis, but there was good awareness of where this technique was valuable and where it was not applicable. Meta analysis technique (OR 3.7, 95\% CI 1.3-10.8, p = 0.02) and assessment for heterogeneity (OR 38.1, 95\%CI 2.1, 688.2, $\mathrm{p}=0.01$ ) was found to be employed significantly more often by Cochrane reviews.

\section{Discussion}

Our study showed that the Cochrane reviews [8-46] were of consistently high methodological quality and had a greater level of assessment for quality of included studies. They always did a meta-analysis $[9,12,17,19-25,27-40,44-$ 46] where applicable. This is reassuring for clinicians who rely on them for decision-making. It is possible that the

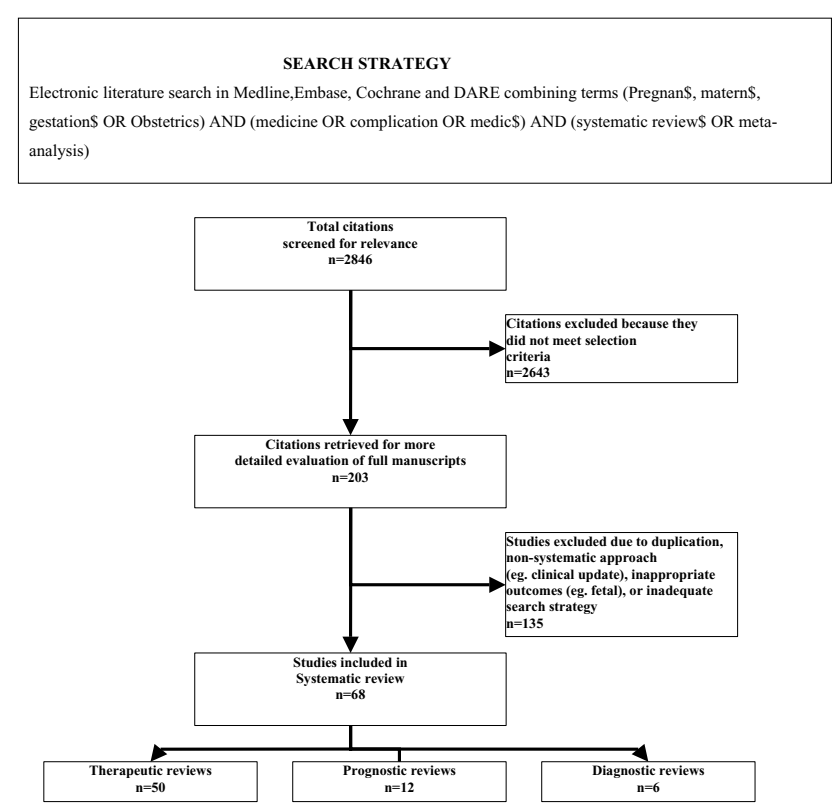

Figure I

Search strategy and study selection process for review of the methodological features of systematic reviews in maternal medicine.

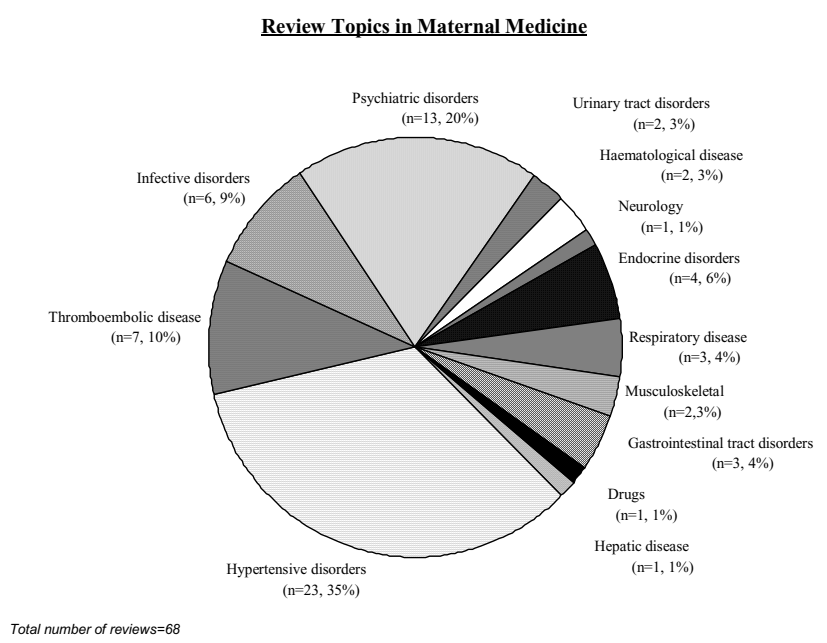

Figure 2

Clinical topics covered by existing maternal medicine reviews. 


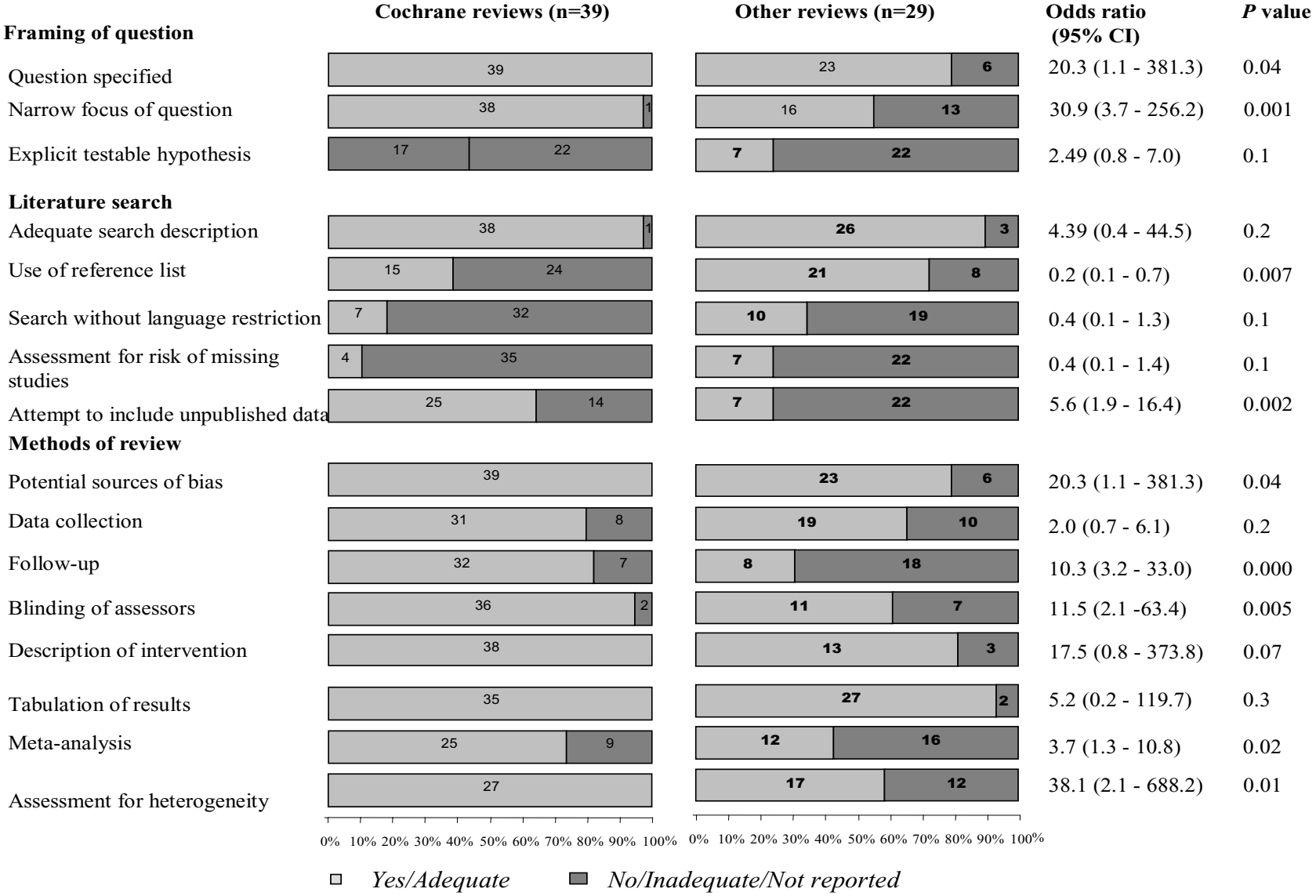

Figure 3

Quality of Cochrane and non Cochrane systematic reviews included in the study.

restriction on the length of published non Cochrane reviews by journals could have influenced their quality scores. However this issue has been addressed by increase in the web publishing of additional material in the electronic format by many journals in recent years.

This work has highlighted that literature searches in reviews are currently generally poor. A search that is not thorough risks giving biased inferences. We identified considerable room for improvement in certain methodological features of non Cochrane reviews. However all the selected reviews were similar in searches without language restriction and assessment for risk of missing studies. Interestingly use of reference list of the selected papers to identify any other eligible studies for inclusion in the review was found to be more frequent in non Cochrane reviews (OR 0.2, 95\% CI 0.1-0.7, p < 0.007). This could be a result of the generic search strategy employed by Cochrane reviews with unclear mention of the use of ref- erence lists in individual reviews. Cochrane reviews were found more likely to attempt to include unpublished data compared to non Cochrane reviews (OR 5.6, 95\% CI 1.9$16.4, \mathrm{p}<0.002)$. This attempt to avoid publication bias is significant as the odds of publication are higher if the results are found to be significant compared to studies with non-significant results.[76]

This study identified areas of maternal medicine that lack good quality systematic reviews. Majority of the reviews were on hypertensive disorders [8,10,11,17,19-23,31$34,37,48,53,55,58,64,65,69,70]$, psychiatry $[15,27,43,47,50-52,56,57,59,61,74,75]$, or thromboembolism [26,42,62-66,68]. Even among these commonly addressed areas, a very narrow spectrum of diseases was covered. For example reviews in psychiatry were solely focussed on depression during pregnancy and reviews in hypertension focussed mainly on pre eclampsia. Reviews for some very common medical problems during preg- 
nancy were missing or of poor quality. We found very few reviews on diabetes mellitus $[12,39,49,73]$ and chronic hypertension and none on thyroid disorders.

With advancement in neonatology and paediatric medicine, more and more women with congenital problems such as congenital heart disease and inherited metabolic diseases are reaching child bearing age and considering pregnancy. There is an urgent need to have some cumulative evidence on management of this high risk group in the best possible way.

This study has some potential limitations. With our strict criteria to include reviews conducted with two publicly available databases, it is possible that some of the good quality reviews in maternal medicine using single database are missed. Another limitation relates to maternal outcome as the main focus of our study. We excluded all those reviews in which association between maternal disease and perinatal outcome was assessed. Keeping in mind the primary goal of an obstetrician being directed towards achieving a healthy and safe outcome for both mother and fetus, good quality evidenced based information on medical problems during pregnancy can only be achieved by reviewing methodological features of all aspects of maternal medicine irrespective of the endpoint. Due to the absence of blinding of the reviewers to the source of the review it is difficult to completely rule out any resultant bias.

\section{Conclusion}

Evidence based healthcare continues to make important contributions to the well being of pregnant women. This study has identified areas in maternal medicine that lack good quality systematic reviews. Overall quality of the existing systematic reviews was variable, with Cochrane reviews better than other reviews. To achieve better understanding and provide high quality obstetric care for pregnant women with medical problems, it is important to ensure that systematic reviews in maternal medicine are conducted to cover wider spectrum of diseases, and are reported at the highest possible quality.

\section{Competing interests}

The author(s) declare that they have no competing interests.

\section{Funding}

None

\section{Authors' contributions}

LS conducted the search, extracted data and drafted the initial version. SJ performed data extraction. ST performed statistical analysis. ST, MK and KSK drafted and approved the final version.

\section{References}

I. Department of Health: Specialised Services National Definition Set: 4 Specialised services for women's health. Department of health 2006 [http://www.dh.gov.uk/en/PolicyAndGuidance/ HealthAndSocialCareTopics/SpecialisedServicesDefinition].

2. Oxman $A D$, Cook $D J$, Guyatt $G H$ : Users' guides to the medical literature. VI. How to use an overview. Evidence-Based Medicine Working Group. JAMA |994, 272:|367-|37|.

3. Sacks HS, Reitman D, Pagano D: Meta-analysis: an update. Mt Sinai J Med 1996, 63:216-224.

4. Petticrew M: Systematic reviews from astronomy to zoology: myths and misconceptions. BMJ 200I, 322:98-10I.

5. Clarke M: The QUORUM statement. Lancet 2000, 355:756-757.

6. Jadad AR, Cook DJ, Jones A, et al:: Methodology and reports of systematic reviews and meta-analyses: a comparison of Cochrane reviews with articles published in paper-based journals. JAMA 1998, 280:278-280.

7. Oxman $A D$, Guyatt $G H$ : Validation of an index of the quality of review articles. J Clin Epidemiol 1991, 44:1271-I 278.

8. Abalos E, Duley L, Steyn DW, Henderson-Smart D: Antihypertensive drug therapy for mild to moderate hypertension during pregnancy. Cochrane Database of Systematic Reviews 2001:CD002252.

9. Adab N, Tudur SC, Vinten J, Williamson P, Winterbottom J: Common antiepileptic drugs in pregnancy in women with epilepsy. Cochrane Database of Systematic Reviews 2004:CD004848.

10. Atallah AN, Hofmeyr G], Duley L: Calcium supplementation during pregnancy for preventing hypertensive disorders and related problems. Cochrane Database of Systematic Reviews 2002:CD001059.

II. Bergel E, Carroli G, Althabe F: Ambulatory versus conventional methods for monitoring blood pressure during pregnancy. Cochrane Database of Systematic Reviews 2002:CD00I 231 .

12. Boulvain M, Stan C, Irion O: Elective delivery in diabetic pregnant women. Cochrane Database of Systematic Reviews 2001:CD001997.

13. Brocklehurst P: Antibiotics for gonorrhoea in pregnancy. Cochrane Database of Systematic Reviews 2002:CD000098.

14. Cuervo LG, Mahomed K: Treatment for iron deficiency anaemia in pregnancy. Cochrane Database of Systematic Reviews 2001:CD003094.

15. Dennis CL, Creedy D: Psychosocial and psychological interventions for preventing postpartum depression. Cochrane Database of Systematic Reviews 2004:CD00I I 34.

16. Burrows RF, Clavisi O, Burrows E: Interventions for treating cholestasis in pregnancy. Cochrane Database of Systematic Reviews 2001:CD000493.

17. Churchill D, Duley L: Interventionist versus expectant care for severe pre-eclampsia before term. Cochrane Database of Systematic Reviews 2002:CD003106.

18. Dodd J, Dare MR, Middleton P: Treatment for women with postpartum iron deficiency anaemia. Cochrane Database of Systematic Reviews 2004:CD004222.

19. Duley L, Henderson-Smart DJ: Drugs for treatment of very high blood pressure during pregnancy. Cochrane Database of Systematic Reviews 2002:CD001449.

20. Duley L, Henderson-Smart D: Magnesium sulphate versus phenytoin for eclampsia. Cochrane Database of Systematic Reviews 2003:CD000I28.

21. Duley L, Henderson-Smart D: Magnesium sulphate versus diazepam for eclampsia. Cochrane Database of Systematic Reviews 2003:CD000I 27.

22. Duley L, Gulmezoglu AM, Henderson-Smart DJ: Magnesium sulphate and other anticonvulsants for women with preeclampsia. Cochrane Database of Systematic Reviews 2003:CD000025.

23. Duley L, Henderson-Smart D, Meher S: Altered dietary salt for preventing pre-eclampsia, and its complications. Cochrane Database of Systematic Reviews 2005:CD005548.

24. French L, Smaill F: Antibiotic regimens for endometritis after delivery. Cochrane Database of Systematic Reviews 2004:CD00 1067.

25. Garner P, Gulmezoglu A: Drugs for preventing malaria-related illness in pregnant women and death in the newborn. Cochrane Database of Systematic Reviews 2002:CD000169. 
26. Gates S, Brocklehurst P, Davis LJ: Prophylaxis for venous thromboembolic disease in pregnancy and the early postnatal period. Cochrane Database of Systematic Reviews 2002:CD001689.

27. Howard LM, Hoffbrand S, Henshaw C, Boath L, Bradley E: Antidepressant prevention of postnatal depression. Cochrane Database of Systematic Reviews 2005:CD004363.

28. Jewell D, Young G: Interventions for nausea and vomiting in early pregnancy. Cochrane Database of Systematic Reviews 2002:CD000I45.

29. Jewell D, Young G: Interventions for treating constipation in pregnancy. Cochrane Database of Systematic Reviews 2001:CD00II42

30. Kroner C, Turnbull D, Wilkinson C: Antenatal day care units versus hospital admission for women with complicated pregnancy. Cochrane Database of Systematic Reviews 200 I:CD00I803.

31. Magee L, Sadeghi S: Prevention and treatment of postpartum hypertension. Cochrane Database of Systematic Reviews 2005:CD00435I

32. Magee LA, Duley L: Oral beta-blockers for mild to moderate hypertension during pregnancy. Cochrane Database of Systematic Reviews 2003:CD002863.

33. Matchaba $P$, Moodley J: Corticosteroids for HELLP syndrome in pregnancy. Cochrane Database of Systematic Reviews 2004:CD002076.

34. Meher S, Abalos E, Carroli G: Bed rest with or without hospitalisation for hypertension during pregnancy. Cochrane Database of Systematic Reviews 2005:CD0035I4.

35. Orton L, Garner P: Drugs for treating uncomplicated malaria in pregnant women. Cochrane Database of Systematic Reviews 2005:CD004912.

36. Quijano CE, Abalos E: Conservative management of symptomatic and/or complicated haemorrhoids in pregnancy and the puerperium. Cochrane Database of Systematic Reviews 2005:CD004077.

37. Rumbold A, Duley L, Crowther C, Haslam R: Antioxidants for preventing pre-eclampsia. Cochrane Database of Systematic Reviews 2005:CD004227.

38. Smaill F: Antibiotics for asymptomatic bacteriuria in pregnancy. Cochrane Database of Systematic Reviews 2001:CD000490.

39. Tuffnell DJ, West J, Walkinshaw SA: Treatments for gestationa diabetes and impaired glucose tolerance in pregnancy. Cochrane Database of Systematic Reviews 2003:CD003395.

40. Vazquez JC, Villar J: Treatments for symptomatic urinary tract infections during pregnancy. Cochrane Database of Systematic Reviews 2003:CD002256.

4I. Walker G]: Antibiotics for syphilis diagnosed during pregnancy. Cochrane Database of Systematic Reviews 200I:CD00I I 43.

42. Walker MC, Ferguson SE, Allen VM: Heparin for pregnant women with acquired or inherited thrombophilias. Cochrane Database of Systematic Reviews 2003:CD003580.

43. Webb RT, Howard L, Abel KM: Antipsychotic drugs for nonaffective psychosis during pregnancy and postpartum. Cochrane Database of Systematic Reviews 2004:CD0044I I.

44. Young G, Jewell D: Interventions for preventing and treating pelvic and back pain in pregnancy. Cochrane Database of Systematic Reviews 2002:CD00II 39.

45. Young G, Jewell D: Topical treatment for vaginal candidiasis (thrush) in pregnancy. Cochrane Database of Systematic Reviews 2001:CD000225.

46. Young G, Jewell D: Interventions for leg cramps in pregnancy. Cochrane Database of Systematic Reviews 2002:CD000 I 21.

47. Boath $E$, Bradley $E$, Henshaw C, Boath $E$ : The prevention of postnatal depression: a narrative systematic review. Journal of Psychosomatic Obstetrics \& Gynecology 2005, 26(3): 185-192.

48. Brien T, Ray JG, Chan WS: Maternal body mass index and the risk of pre eclampsia: a systematic overview. Epidemiology 2003, I 4(3):368-374.

49. Brody SC, Harris R, Lohr K: Screening for gestational diabetes: a summary of the evidence for the U.S. Preventive Services Task Force. Obstetrics \& Gynecology 2003, I 0 I (2):380-392

50. Beck CT: Predictors of postpartum depression: an update. Nursing Research 200I, 50(5):275-285.

5I. Austin MP, Priest SR: Clinical issues in perinatal mental health: new developments in the detection and treatment of perinatal mood and anxiety disorders. Acta Psychiatrica Scandinavica 2005, I I 2(2):97-104
52. Beck CT: Postpartum depression: a metasynthesis. Qualitative Health Research 2002, I 2(4):453-472.

53. Coomarasamy A, Papaioannou S, Gee H, Khan KS: Aspirin for the prevention of preeclampsia in women with abnormal uterine artery Doppler: a meta-analysis. Obstetrics \& Gynecology 200I, 98(5 Pt I):86I-866.

54. Coomarasamy A, Honest H, Papaioannou S, Gee H, Khan KS: Aspirin for prevention of preeclampsia in women with historical risk factors: a systematic review. Obstetrics \& Gynecology 2003, I0I(6): I319-1332

55. Conde-Agudelo A, Villar J, Lindhmeimer M: World health organization syustematic review of screening tests for pre eclampsia. Obstetrics \& Gynecology 2004, 104:|367-|39|.

56. Dennis CL: Preventing postpartum depression part II: A critical review of nonbiological interventions. Canadian Journal of Psychiatry - Revue Canadienne de Psychiatrie 2004, 49(8):526-538.

57. Dennis CL: Preventing postpartum depression part I: a review of biological interventions. Canadian Journal of Psychiatry - Revue Canadienne de Psychiatrie 2004, 49(7):467-475.

58. Duckitt K, Harrington D: Risk factors for pre-eclampsia at antenatal booking: systematic review of controlled studies. $B M$ 2005, 330(749I):565.

59. Eberhard-Gran M, Eskild A, Tambs K, Opjordsmoen S, Samuelsen SO: Review of validation studies of the Edinburgh Postnatal Depression Scale. Acta Psychiatrica Scandinavica 200I, 104(4):243-249.

60. Gluck JC, Gluck PA: Asthma controller therapy during pregnancy. American Journal of Obstetrics \& Gynecology 2005, 192(2):369-380.

6I. Goodman JH: Postpartum depression beyond the early postpartum period. JOGNN - Journal of Obstetric, Gynecologic, \& Neonatal Nursing 2004, 33(4):410-420

62. Greer IA, Nelson-Piercy C: Low-molecular-weight heparins for thromboprophylaxis and treatment of venous thromboembolism in pregnancy: a systematic review of safety and efficacy. Blood 2005, 106(2):40I-407.

63. Kujovich JL: Thrombophilia and pregnancy complications. American Journal of Obstetrics and Gynecology 2004, 191:412-424.

64. Kosmas IP, Tatsioni A, loannidis JP: Association of Leiden mutation in factor $\mathbf{V}$ gene with hypertension in pregnancy and pre-eclampsia: a meta-analysis. Journal of Hypertension 2003, 2I(7): |22|-|228

65. Kosmas IP, Tatsioni A, loannidis JP: Association of C677T polymorphism in the methylenetetrahydrofolate reductase gene with hypertension in pregnancy and pre-eclampsia: a metaanalysis. Journal of Hypertension 2004, 22(9): 1655-1662.

66. Kovalevsky G, Clarisa R, Gracia R, Jesse AB, Mary DS, Kurt TB: Evaluation of the association between hereditary thrombophilias and recurrent pregnancy loss: a meta-analysis. Archives Internal Medicine 2004, 164:558-562.

67. Kwon HL, Belanger K, Bracken MB: Effect of pregnancy and stage of pregnancy on asthma severity: a systematic review. American Journal of Obstetrics \& Gynecology 2004, | 90(5): | 20I-12 I0.

68. Lassere M, Empson M: Treatment of antiphospholipid syndrome in pregnancy - a systematic review of randomized therapeutic trials. Thrombosis Research 2004, I | 4(5-6):419-426.

69. Magee LA, Cham C, Waterman EJ, Ohlsson A, von DP: Hydralazine for treatment of severe hypertension in pregnancy: metaanalysis. $B M / 2003,327(742 I): 955-960$.

70. Magee LA, Bull SB, Koren G, Logan A: The generalizability of trial data; a comparison of $\beta$-blockers in pregnancy. European Journal of Obstetrics \& Gynecology and Reproductive Biology 200I, 94:205-210

71. Murphy VE, Clifton VL, Gibson PG: Asthma exacerbations during pregnancy: incidence and association with adverse pregnancy outcomes. Thorax 2006, 6I(2):169-176.

72. Rayburn WF, Bogenschutz MP: Pharmacotherapy for pregnant women with addictions. American Journal of Obstetrics \& Gynecology 2004, I 9 I(6): | $885-1897$.

73. Scott DA, Loveman E, McIntyre L, Waugh N: Screening for gestational diabetes: a systematic review and economic evaluation. Health Technology Assessment 2002, 6(I I):I-16I.

74. Austin MP, Lumley J: Antenatal screening for postnatal depression: a systematic review. Acta Psychiatrica Scandinavica 2003, 107(I):10-17. 
75. Austin MP: Targeted group antenatal prevention of postnatal depression: a review. Acta Psychiatrica Scandinavica 2003, 107(4):244-250.

76. Egger M, Smith GD: Meta-analysis bias in location and selection of studies. BMJ 1998, 316:61-66.

\section{Pre-publication history}

The pre-publication history for this paper can be accessed here:

http://www.biomedcentral.com/1741-7015/5/10/prepub

Publish with Biomed Central and every scientist can read your work free of charge

"BioMed Central will be the most significant development for disseminating the results of biomedical research in our lifetime. " Sir Paul Nurse, Cancer Research UK

Your research papers will be:

- available free of charge to the entire biomedical community

- peer reviewed and published immediately upon acceptance

- cited in PubMed and archived on PubMed Central

- yours - you keep the copyright

Submit your manuscript here:

http://www.biomedcentral.com/info/publishing_adv.asp 